\title{
The Thrombopoietin Receptor Agonist Lusutrombopag Is Effective for Patients with Chronic Liver Disease and Impaired Renal Function
}

\author{
Hirohito Takeuchi ${ }^{1}$, Yoshihiro Furuichi ${ }^{1,2}$, Yu Yoshimasu ${ }^{1}$, Yoshitaka Kasai ${ }^{1}$, \\ Masakazu Abe ${ }^{1}$, Katsutoshi Sugimoto ${ }^{1}$ and Takao Itoi $^{1}$ \\ ${ }^{1}$ Department of Gastroenterology and Hepatology, Tokyo Medical University, Tokyo, Japan \\ ${ }^{2}$ Department of Gastroenterology and Hepatology, Niizashiki Central General Hospital, Saitama, Japan
}

Background: The thrombopoietin (TPO) receptor agonist lusutrombopag was developed to treat thrombocytopenia in chronic liver disease (CLD). However, its effectiveness remains unclear. The purpose of this study was to assess the efficacy of lusutrombopag and identify predictors associated with increase in platelet count.

Methods: Eighty CLD patients with thrombocytopenia were enrolled. The primary endpoint was a satisfactory increase in platelets (greater than $1.0 \times 10^{4} / \mu \mathrm{L}$ from baseline) in the absence of platelet transfusion. The secondary endpoints were response rate (an increase of greater than $1.0 \times 10^{4} / \mu \mathrm{L}$ from baseline), independent predictors of increase in platelets, and the superiority of lusutrombopag over platelet transfusion.

Results: The primary endpoint was achieved in $93.8 \%$ (75 of 80) patients. The response rate was $96.2 \%$ (77 of 80 ). Renal function parameters (blood urea nitrogen, creatinine, eGFR) were significantly negatively associated with platelet count $(p=0.033,0.049$, and 0.0014 , respectively) and were identified as independent predictors by multiple regression analysis $(p=0.049,0.0023$, and 0.0016 , respectively). The median increase in platelet count was significantly higher after lusutrombopag than after platelet transfusion $(41,000$ vs. $12,000 / \mu \mathrm{L}, p=0.015)$.

Conclusion: Lusutrombopag was more effective than platelet transfusion for CLD patients, and renal function independently predicted increase in platelet count. Renal function parameters were significantly associated with platelet count. (J Nippon Med Sch 2020; 87: 325-333)

Key words: lusutrombopag, thrombopoietin receptor agonist, thrombocytopenia, chronic liver disease, platelet transfusion

\section{Introduction}

Thrombocytopenia is present in about $80 \%$ of patients with chronic liver disease $(\mathrm{CLD})^{1,2}$. Hepatocellular carcinoma and esophageal/gastric varices frequently develop in CLD patients and require invasive treatments such as radiofrequency ablation (RFA), transcatheter arterial chemoembolization (TACE), endoscopic injection sclerotherapy (EIS), and endoscopic variceal ligation (EVL). Although active bleeding sometimes occurs in CLD patients with thrombocytopenia ${ }^{3}$, there are no clear criteria for platelet transfusion in such cases. Moreover, platelet transfusion carries the risk of viral infection and allergic or nonhemolytic reaction ${ }^{4,5}$. The increase in platelet count is often insufficient in CLD patients, even after a large transfusion. Moreover, transfusion is contraindicated in platelet-refractory patients. Branched-chain amino acidenriched nutrients can increase platelet count in CLD patients, but the effect is limited ${ }^{6}$. Although thrombopoietin (TPO) receptor agonists are approved for use in patients with idiopathic thrombocytopenic purpura ${ }^{7,8}$, eltrombopag and romiplostim have not yet been approved for use in CLD patients, because of the risk of thromboem-

Correspondence to Yoshihiro Furuichi, MD, PhD, Department of Gastroenterology and Hepatology, Tokyo Medical University, 6-7-1 Nishi-Shinjuku, Shinjuku-ku, Tokyo 160-0023, Japan

E-mail: furuich@tokyo-med.ac.jp

https://doi.org/10.1272/jnms.JNMS.2020_87-603

Journal Website (https://www.nms.ac.jp/sh/jnms/) 
bolic side effects ${ }^{9}$. Lusutrombopag was recently approved for use in CLD patients with thrombocytopenia in Ja$\operatorname{pan}^{10}$, and both lusutrombopag and avatrombopag have been approved for use in the United States ${ }^{11}$. Lusutrombopag operates on the transmembrane domain of human TPO receptors and induces platelet production ${ }^{12,13}$. A phase 2B study in Japan showed that lusutrombopag 3 mg given daily for 7 days increased platelet counts in 46 CLD patients with severe thrombocytopenia ${ }^{10}$, and lusutrombopag is now used for treatment of thrombocytopenia in CLD worldwide.

Unfortunately, few studies have examined the effectiveness of lusutrombopag. Therefore, we investigated whether administration of lusutrombopag sufficiently increased platelet count in a large sample of CLD patients. Factors associated with increased platelet count after treatment with lusutrombopag were identified, and the effectiveness of lusutrombopag and platelet transfusion was compared.

\section{Patients and Methods}

\section{Study Design and Patient Selection}

The primary endpoint of this observational study lusutrombopag effectiveness, ie, the proportion of cases with a satisfactory increase in platelet count (an increase greater than $1.0 \times 10^{4} / \mu \mathrm{L}$ from baseline) in the absence of platelet transfusion. The secondary endpoints were 1) the number of days required to reach maximum platelet count after administration; 2) the proportion of responders (response was classified as strong: increase of $>4.0 \times$ $10^{4} / \mu \mathrm{L}$ from baseline; good, increase of $2.0-4.0 \times 10^{4} / \mu \mathrm{L}$; fair, increase of 1.0-2.0 $\times 10^{4} / \mu \mathrm{L}$; or weak, increase of $<1.0$ $\times 10^{4} / \mu \mathrm{L}$ ) and response rate showed an increase of greater than $1.0 \times 10^{4} / \mu \mathrm{L}$ from baseline; 3) predictors associated with increased platelet count; 4) comparison of lusutrombopag and platelet transfusion in relation to increase in platelet count, and; 5) adverse events (AEs).

Thromboembolic events were evaluated by ultrasonography, computed tomography, or magnetic resonance images obtained 10 to 14 days after the start of lusutrombopag. Severity of AEs was classified according to the Common Terminology Criteria for Adverse Events V4.0 (grade 1-4). On the day of invasive treatment or examination, platelet transfusion was not performed for patients with a platelet count greater than $10.0 \times 10^{4} / \mu \mathrm{L}$ but was always performed if the platelet count was less than $5.0 \times 10^{4} / \mu \mathrm{L}$. In patients with a platelet count between $5.0 \times 10^{4} / \mu \mathrm{L}$ and $10.0 \times 10^{4} / \mu \mathrm{L}$, the necessity of a platelet transfusion was decided after assessing the risk of bleed- ing in the patient or the invasiveness of the treatment to be performed.

The study protocol was approved by the Clinical Research Ethics Committee of Tokyo Medical University (Approval number: 2018042) and conformed to the principles of the Helsinki Agreement. Written informed consent was obtained from all patients before their participation in the study. The study was registered at the University Hospital Medical Information Network Center in Japan (UMIN ID: 000032777).

The inclusion criteria were age 20 years or older, CLD accompanied by thrombocytopenia (platelet count, $<10.0$ $\times 10^{4} \mu \mathrm{L}$ ), and scheduled invasive treatment or examination. The exclusion criteria were history of thrombosis, refractory hepatic encephalopathy, Child-Pugh class C, and high bilirubin level ( $>5 \mathrm{mg} / \mathrm{dL})$. Invasive treatment or examination was defined as RFA, TACE, EIS, EVL, balloon-occluded retrograde transvenous obliteration, endoscopic mucosal resection, dental treatment, or surgical treatment. These invasive examinations and treatments were performed between 10 and 16 days after the start of drug treatment. Lusutrombopag $3 \mathrm{mg}$ was administered daily for 7 days, and blood testing was performed on days 5-7 and days 10-6 before invasive treatment. Ultimately, 80 CLD patients scheduled for invasive treatment (or examination) were enrolled in this observational study (Table 1).

\section{Statistical Analysis}

The required sample size was determined after reviewing the results of an earlier study ${ }^{10}$. The statistical software used was EZR (Easy R) version 1.27 (Saitama Medical Center, Jichi Medical University, Japan). In the previous report, $20.0 \%$ of patients did not require platelet transfusion in the placebo group, while $81.3 \%$ of those receiving $3 \mathrm{mg} /$ day lusutrombopag group did. Therefore, in the present study, assuming an $\alpha$-error of 0.05 and a power of 0.80 , the required sample size was 26 patients. Moreover, assuming a response rate of $81.3 \%$ and a confidence interval width (difference) of less than 0.2 , the required sample size was 62 patients. Initially, 82 CLD patients with thrombocytopenia were deemed eligible to participate in the study. Two of these patients were subsequently hospitalized elsewhere, however, for treatment of another illness. The final analysis thus included 80 patients (Table 1).

Other analyses were performed with SPSS 25.0J software (SPSS Inc., Chicago, IL, USA). Values are expressed as median and range. The Mann-Whitney U-test was used to compare patient blood results. The chi-square 
Table 1 Baseline patient characteristics

\begin{tabular}{lc}
\hline \multicolumn{1}{c}{ Characteristics } & All patients $(\mathrm{n}=80)$ \\
\hline Age, yr (median, range) & $67.5(36-86)$ \\
Male, n. (\%) & $56(70)$ \\
Cause (HBV /HCV / ALC/NASH/other) & $3 / 33 / 23 / 9 / 12$ \\
Disease (HCC/EV/GV/other) & $43 / 19 / 4 / 14$ \\
Treatment (EIS/TACE/RFA/other) & $21 / 19 / 22 / 18$ \\
Blood test results before lusutrombopag treatment & \\
Platelets $\left(\times 10^{4} / \mu \mathrm{L}\right)$ & $6.1(1.4-9.3)$ \\
PT-INR & $1.1(0.8-2.7)$ \\
AST (IU/L) & $41(15-184)$ \\
ALT (IU/L) & $29(7-253)$ \\
Total bilirubin (mg/dL) & $1.0(0.4-3.9)$ \\
Albumin (g/dL) & $3.6(2.2-4.4)$ \\
BUN (mg/dL) & $15.9(4.3-58.0)$ \\
Creatinine (mg/dL) & $0.8(0.4-9.4)$ \\
eGFR (mL/min/1.73 m²) & $73.4(4.8-161.7)$ \\
Child-Pugh (A/B/C) & $66 / 14 / 0$ \\
Child-Pugh score & $5.0(5.0-9.0)$ \\
History of platelet transfusion, n. (\%) & $10(12.5)$ \\
Spleen index & $25.6(9.9-50.2)$ \\
\hline
\end{tabular}

Data are expressed as median and range.

$\mathrm{yr}=$ years, $\mathrm{HBV}=$ hepatitis $\mathrm{B}$ virus, $\mathrm{HCV}=$ hepatitis $\mathrm{C}$ virus, $\mathrm{ALC}=$ alcoholic hepatitis, NASH = nonalcoholic steatohepatitis, HCC = hepatocellular carcinoma, EV = esophageal varices, GV = gastric varices, EIS = endoscopic injection sclerotherapy, $\mathrm{TACE}=$ transcatheter arterial chemoembolization, $\mathrm{RFA}=$ radiofrequency ablation, $\mathrm{AST}=$ aspartate aminotransferase, $\mathrm{ALT}=$ alanine aminotransferase, BUN = blood urea nitrogen, eGFR = estimated glomerular filtration rate

test was used for comparison between sexes. Factors associated with an increase in platelet count were identified by using Spearman rank correlation coefficients. Furthermore, significant factors were analyzed by multiple regression analysis. Factors that predicted resistance to lusutrombopag (cases in which platelet count did not increase by more than $1.0 \times 10^{4} / \mu \mathrm{L}$ from baseline) were identified by Cox proportional regression analysis. A $p$ value of $<0.05$ was considered to indicate a statistically significant difference.

\section{Results}

\section{Primary Efficacy Endpoints}

A total 78 of 80 patients $(97.5 \%)$ did not require platelet transfusion, and platelet count increased by more than $1.0 \times 10^{4} / \mu \mathrm{L}$ from baseline in 77 of 80 (96.3\%) patients. Accordingly, 75 of 80 patients (93.8\%) met both efficacy criteria (Fig. 1a).

\section{Secondary Efficacy Endpoints}

The median number of days (range) required to reach maximum platelet count after commencement of administration of lusutrombopag was 14 (7-22), and the median number of days to sustained effectiveness (an increase in platelet count greater than $1.0 \times 10^{4} / \mu \mathrm{L}$ from baseline) of lusutrombopag after starting medical treatment was 19 (5-58). The median duration of sustained effect of lusutrombopag after reaching maximum platelet count was 9 days (3-34) and a sufficient platelet increase was obtained. The median value was $4.9 \times 10^{4} / \mu \mathrm{L}(-0.3$ to 30.1$)$ (Table 2, Fig. 2).

Response was classified as strong in 49 of 80 patients $(61.3 \%)$, good in 20 of $80(25 \%)$, fair in 8 of $80(10.0 \%)$, and weak in 3 of $80(3.8 \%)$ (Fig. 1b). The rate of response, ie, an increase greater than $1.0 \times 10^{4} / \mu \mathrm{L}$ from baseline, was $96.2 \%$ (77 of 80 ). Three patients with a weak response did not receive platelet transfusion before invasive treatment (Fig. 1a, 1b), because their baseline platelet counts were relatively high $\left(7.1,8.1\right.$, and $\left.8.6 \times 10^{4} / \mu \mathrm{L}\right)$ (Table 3 ). In these patients, no bleeding occurred after invasive treatment.

Correlations between increase in platelet count and blood testing variables were investigated (Table 4). Correlations between increase in platelet count and spleen index score, as determined by abdominal ultrasonogra- 
phy, were also investigated. Blood urea nitrogen (BUN), creatinine, and estimated glomerular filtration rate (eGFR) were significantly correlated with increase in platelet count ( $p=0.047,0.099$, and $<0.001$, respectively). In multiple regression analysis, these factors were significantly independently associated with increase in platelet count after the start of lusutrombopag $(p=0.049,0.0033$, and $<0.001$, respectively) (Table 4 ).

Patients were divided into 2 groups, in relation to response to lusutrombopag (strong/good/fair vs. weak), to identify predictors associated with nonresponse to the drug (Table 3). Univariate analysis revealed significant differences between groups in platelet count, aspartate aminotransferase (AST), alanine aminotransferase (ALT), and albumin values before the start of lusutrombopag ( $p$ $=0.018,0.03,0.02$, and 0.018, respectively). Significant differences were also observed in AST and ALT values after the start of lusutrombopag ( $p=0.028$ and 0.022 , respectively). However, multivariate analysis showed no

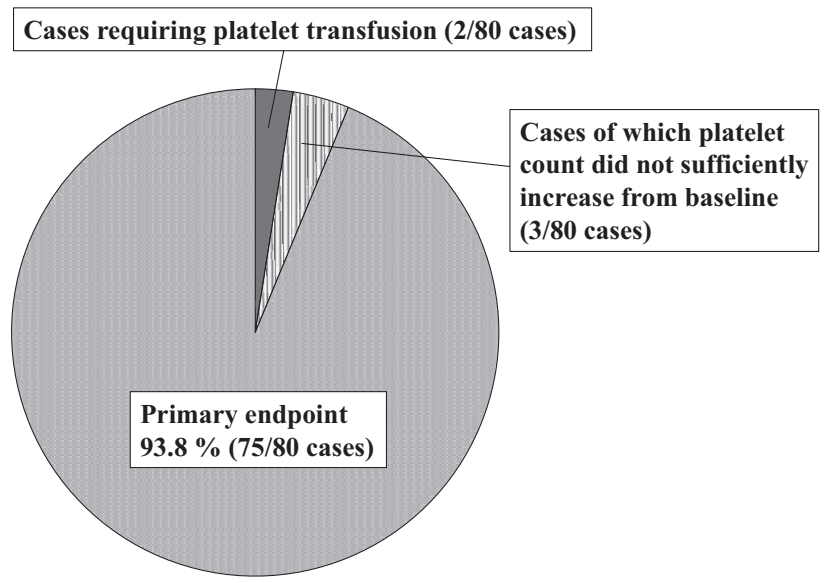

Fig. 1a Patients meeting primary endpoint The primary endpoint of this observation study was the proportion of cases satisfying the following criteria: a sufficient platelet increase (increase greater than $1.0 \times 10^{4} / \mu \mathrm{L}$ from baseline) in the absence of platelet transfusion. Two patients required platelet transfusion, and platelet count did not increase by more than $1.0 \times 10^{4} / \mu \mathrm{L}$ from baseline in 3 patients. Both criteria were met in 75 of 80 patients (93.8\%). significant difference in these factors.

Ten patients had previously undergone platelet transfusion. The increase in platelet count was compared for platelet transfusion and lusutrombopag treatment in these patients. After platelet transfusion, median platelet count increased by just $12,000 / \mu \mathrm{L}$ (from 41,000 to 55,000 / $\mu \mathrm{L})$, and there was no significant difference before and after transfusion $(p=0.059)$. In patients receiving lusutrombopag, however, the median significantly increased from 42,500 to $76,000 / \mu \mathrm{L}(p=0.0051)$. This increase in platelet count was significantly greater than that after platelet transfusion ( $p=0.015)$ (Fig. 3).

Analysis of AEs showed no portal venous thrombosis in any patient. The incidence of AEs was 12.5\% (10/80 patients), and AEs comprised abdominal pain, headache, constipation, itch, cough, palpitation, and hypertension. No severe AEs were observed (Table 5).

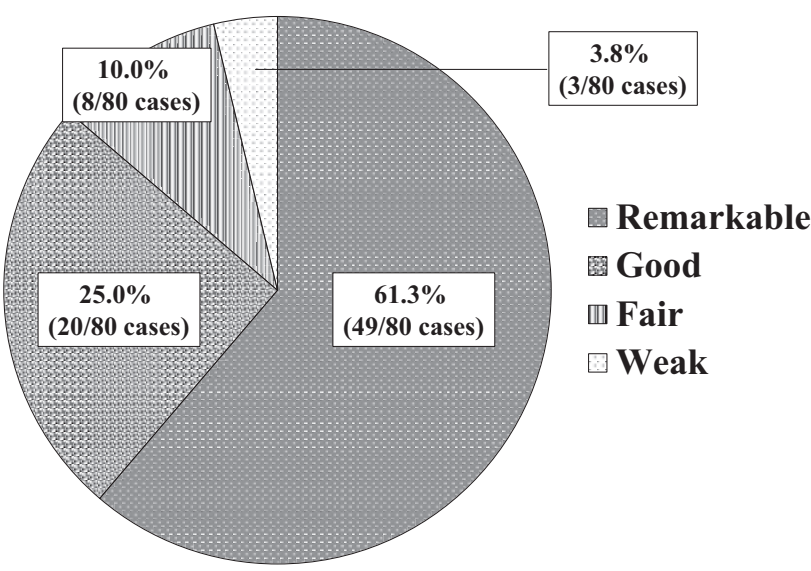

Fig. 1b Proportion of responders to all patients The proportions of responders are shown. Response was classified as strong (increase of $>4.0 \times 10^{4} / \mu \mathrm{L}$ from baseline) in 49 of 80 patients $(61.3 \%)$, good (increase of 2.0-4.0 $\times$ $\left.10^{4} / \mu \mathrm{L}\right)$ in 20 of $80(25 \%)$, fair (increase of $1.0-2.0 \times 10^{4} / \mu \mathrm{L}$ ) in 8 of $80\left(10.0 \%\right.$ ), and weak (increase of $<1.0 \times 10^{4} / \mu \mathrm{L}$ ) in 3 of $80(3.8 \%)$.

Table 2 Effect after lusutrombopag treatment

\begin{tabular}{lc}
\hline & Median number (range) \\
\hline Interval to maximum platelet count after start of lusutrombopag, days & $14(7-22)$ \\
Duration of effect after start of lusutrombopag treatmenta), days & $19(5-58)$ \\
Duration of lusutrombopag effect after reaching Max PLT count, days & $9(3-34)$ \\
Increase in PLT count $(/ \mu \mathrm{L})$ & $4.9 \times 10^{4}(-0.3-30.1)$ \\
\hline
\end{tabular}

a) With platelet count increasing by more than $1.0 \times 10^{4} / \mu \mathrm{L}$ from baseline.

Max: maximum, PLT: platelet 


\section{Discussion}

Thrombocytopenia can lead to serious complications in CLD patients. Massive bleeding is frequently observed

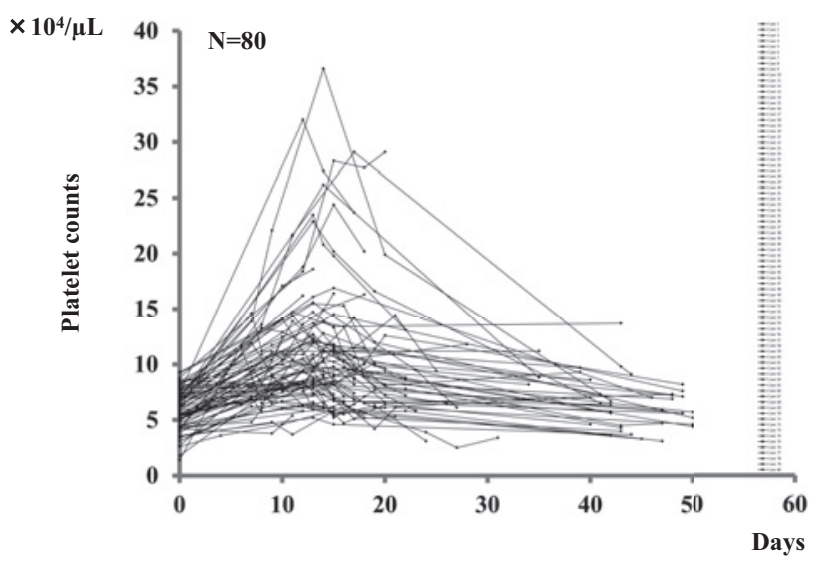

Fig. 2 Time course of platelet count after lusutrombopag administration

Data are medians.

Median number of days to maximum platelet count after starting lusutrombopag was 14 (7-22); the median number of days to the end of effect (platelet increase of more than $1.0 \times 10^{4} / \mu \mathrm{L}$ from baseline) was 19 (5-58). Median duration of effect after maximum platelet count was 9 days (3-34). The median increase in platelet count was $4.9 \times$ $10^{4} / \mu \mathrm{L}$ (-0.3 to 30.1) (Table 2). during invasive treatment and increases the interval to recovery of hemostasis ${ }^{14}$. There is no consensus, however, on the appropriate platelet count in CLD patients with thrombocytopenia. In Japan, platelet transfusion tends to be performed for patients with a platelet count less than $5.0 \times 10^{4} / \mu \mathrm{L}$, but this cut-off value is controversial. One study reported that 10 of $32(32 \%)$ patients with a platelet count less than $7.5 \times 10^{4} / \mu \mathrm{L}$ had procedure-related bleeding ${ }^{3}$. Moreover, bleeding from esophageal varices was seen even in patients with a platelet count greater than $10.0 \times 10^{4} / \mu \mathrm{L}^{15}$. In the past, the standard approach was to perform platelet transfusion in such patients. However, transfusion failure occurred at least once in $49.6 \%$ of such patients, and such failure is considered a clinical marker of bleeding and worse patient survival ${ }^{16}$. Moreover, prophylactic platelet transfusion induced side effects such as lung injury, sepsis, bacteria contamination, and $\mathrm{ABO}$-incompatible transfusion and a large increase in treatment $\operatorname{costs}^{5,17,18}$. This explains why an alternative has been sought to increase platelet count in CLD patients scheduled to undergo repeated invasive treatment.

In the ELEVATE study, the effectiveness of administering the TPO receptor-agonist eltrombopag for 14 days in CLD patients with thrombocytopenia was prospectively

Table 3 Treatment resistance factors to lusutrombopag

\begin{tabular}{|c|c|c|c|c|}
\hline Characteristics & $\begin{array}{c}\text { Responder } \\
(\text { Strong + Good + } \\
\text { Fair group, } \mathrm{n}=77)\end{array}$ & $\begin{array}{c}\text { Nonresponder } \\
(\text { Weak group, } n=3)\end{array}$ & $\begin{array}{l}\text { Mann-Whitney } \\
\text { U-test } p \text {-value }\end{array}$ & $\begin{array}{c}\text { Cox } \\
\text { proportional } \\
\text { hazards } \\
p \text {-value }\end{array}$ \\
\hline \multicolumn{5}{|c|}{ Blood test - before Lusutrombopag } \\
\hline Platelets $\left(\times 10^{4} / \mu \mathrm{L}\right)$ & $5.9(1.4-9.3)$ & $8.1(7.8-8.6)$ & 0.018 & 0.97 \\
\hline PT-INR & $1.09(0.81-2.7)$ & $1.01(0.99-1.03)$ & 0.137 & \\
\hline AST (IU/L) & $41(15-184)$ & $73(65-73)$ & 0.030 & 0.98 \\
\hline ALT (IU/L) & $27(7-253)$ & $61(61-70)$ & 0.020 & 0.98 \\
\hline Total bilirubin (mg/dL) & $0.97(0.35-3.87)$ & $0.76(0.46-0.95)$ & 0.20 & \\
\hline Albumin (g/dL) & $3.6(2.2-4.4)$ & $2.9(2.6-3.0)$ & 0.018 & 0.97 \\
\hline BUN (mg/dL) & $16(4.3-58.0)$ & $10.9(10.7-20.0)$ & 0.543 & \\
\hline Creatinine (mg/dL) & $0.79(0.35-9.4)$ & $0.68(0.65-1.2)$ & 0.86 & \\
\hline eGFR (mL/min/1.73 m²) & $73.1(4.8-161)$ & $90.0(45.0-92.7)$ & 0.80 & \\
\hline \multicolumn{5}{|c|}{ Blood test - after Lusutrombopag } \\
\hline PT-INR & $1.09(0.89-2.2)$ & $1.01(0.98-1.1)$ & 0.20 & \\
\hline AST (IU/L) & $41(18-428)$ & $87(55-93)$ & 0.028 & 0.97 \\
\hline $\operatorname{ALT}(\mathrm{IU} / \mathrm{L})$ & $27(10-367)$ & $59(53-60)$ & 0.022 & 0.97 \\
\hline Total bilirubin (mg/dL) & $0.89(0.31-4.1)$ & $0.70(0.63-1.3)$ & 0.72 & \\
\hline Albumin (g/dL) & $3.5(2.4-4.4)$ & $3.0(2.5-3.4)$ & 0.096 & \\
\hline Spleen Index $\left(\mathrm{cm}^{2}\right)$ & $25.9(9.9-50.2)$ & $24.1(20.2-21.6)$ & 0.20 & \\
\hline
\end{tabular}

Data are expressed as median and range. The Mann-Whitney U-test was used to compare values in univariate analysis. Cox proportional hazard regression analysis was performed as multivariate analysis. A $p$-value of $<0.05$ was considered to indicate a statistically significant difference.

AST $=$ aspartate aminotransferase, ALT = alanine aminotransferase, $\mathrm{BUN}=$ blood urea nitrogen, $\mathrm{eGFR}=$ estimated glomerular filtration rate 
Table 4 Correlation between increase in platelet count from baseline and each factor

\begin{tabular}{|c|c|c|c|}
\hline Factors $(\mathrm{n}=80)$ & $\begin{array}{l}\text { Spearman correlation } \\
\text { coefficient }(\mathrm{r})\end{array}$ & $p$-value & $\begin{array}{l}\text { Multiple regression } \\
\text { analysis } p \text {-value }\end{array}$ \\
\hline \multicolumn{4}{|c|}{ Blood test - before lusutrombopag } \\
\hline White blood cell $(/ \mu \mathrm{L})$ & 0.12 & 0.30 & \\
\hline Hemoglobin (g/dL) & -0.13 & 0.24 & \\
\hline Platelets $\left(\times 10^{4} / \mu \mathrm{L}\right)$ & 0.008 & 0.95 & \\
\hline PT-INR & -0.091 & 0.43 & \\
\hline AST (IU/L) & 0.080 & 0.48 & \\
\hline $\operatorname{ALT}(\mathrm{IU} / \mathrm{L})$ & 0.13 & 0.27 & \\
\hline Total bilirubin (mg/dL) & 0.0003 & 0.99 & \\
\hline Albumin (g/dL) & -0.11 & 0.34 & \\
\hline BUN (mg/dL) & 0.22 & 0.047 & 0.049 \\
\hline Creatinine (mg/dL) & 0.19 & 0.099 & 0.0033 \\
\hline eGFR $\left(\mathrm{mL} / \mathrm{min} / 1.73 \mathrm{~m}^{2}\right)$ & -0.36 & $<0.001$ & $<0.001$ \\
\hline Ammonia $(\mu \mathrm{g} / \mathrm{dL})$ & -0.005 & 0.97 & \\
\hline Child-Pugh score & 0.058 & 0.61 & \\
\hline \multicolumn{4}{|c|}{ Blood test - after lusutrombopag } \\
\hline PT-INR & -0.16 & 0.15 & \\
\hline AST (IU/L) & 0.17 & 0.14 & \\
\hline $\operatorname{ALT}(\mathrm{IU} / \mathrm{L})$ & 0.031 & 0.79 & \\
\hline Total bilirubin (mg/dL) & -0.072 & 0.52 & \\
\hline Albumin (g/dL) & -0.14 & 0.23 & \\
\hline Spleen Index $\left(\mathrm{cm}^{2}\right)$ & -0.20 & 0.082 & \\
\hline
\end{tabular}

Correlations of increase in platelet count with each variable were investigated. Spearman correlation coefficients are expressed as $\mathrm{r}$ values. Multiple regression analysis was performed as multivariate analysis. A $p$-value of $<0.05$ was considered to indicate a statistically significant difference.

AST $=$ aspartate aminotransferase, ALT $=$ alanine aminotransferase, $\mathrm{BUN}=$ blood urea nitrogen, eGFR = estimated glomerular filtration rate

investigated in a multicenter, double-blinded, placebocontrolled phase 3 trial. In that study, $72 \%$ of patients did not require platelet transfusion after eltrombopag. Thrombotic events were observed in 6 patients in the eltrombopag group, however, so use in CLD patients was put on hold because of safety concerns ${ }^{9}$. In another phase 2B trial of lusutrombopag, lusutrombopag $3 \mathrm{mg}$ given daily or 7 days caused no thrombotic events, and efficacy was sufficient $(81.3 \%$ of patients did not require platelet transfusion). On the basis of these results, lusutrombopag was licensed, for the first time worldwide, for use in CLD patients with thrombocytopenia by the Pharmaceuticals and Medical Devices Agency in Japan, in September $2015^{10,19}$. After the lusutrombopag study, avatrombopag was approved by the US FDA in May 2018 for use in adults with thrombocytopenia secondary to CLD who were scheduled to undergo a procedure. This approval was based on the ADAPT-1 and ADAPT-2 clinical trials ( $n=435$ ), which investigated the use of avatrombopag at 2 doses, 40 and $60 \mathrm{mg}(88.1 \%$ and $87.9 \%$, respectively, of patients did not require platelet transfusion). In the
ADAPT-2 trial, there was one case of portal vein thrombosis after avatrombopag treatment ${ }^{11}$.

In the present study, $97.5 \%$ of patients did not require platelet transfusion. This proportion was much higher than those of the 3 earlier studies described above. This may have been because the present baseline platelet count (median, $6.1 \times 10^{4} / \mu \mathrm{L}$ ) was higher than those of previous studies. The median increase in platelet count was surprisingly high, however $\left(>4.9 \times 10^{4} / \mu \mathrm{L}\right)$ (Table 2$)$, as was the proportion of responders (increase greater than $1.0 \times 10^{4} / \mu \mathrm{L}$ from baseline): $96.2 \%$ (Fig. 1b). Taken together, these findings indicate that lusutrombopag is very effective for CLD patients. In the 10 patients with a history of both platelet transfusion and lusutrombopag use, the increase in platelet count was significantly greater during lusutrombopag treatment than after platelet transfusion (Fig. 3). To our knowledge, only 1 study (phase 3 study) reported that lusutrombopag was superior to platelet transfusion in increasing platelet count in CLD patients ${ }^{19}$. Therefore, we believe that the present results are of great value in the management of CLD pa- 
tients for whom invasive treatment is planned. Moreover, the increase in platelet count persisted far longer after administration of lusutrombopag than after platelet

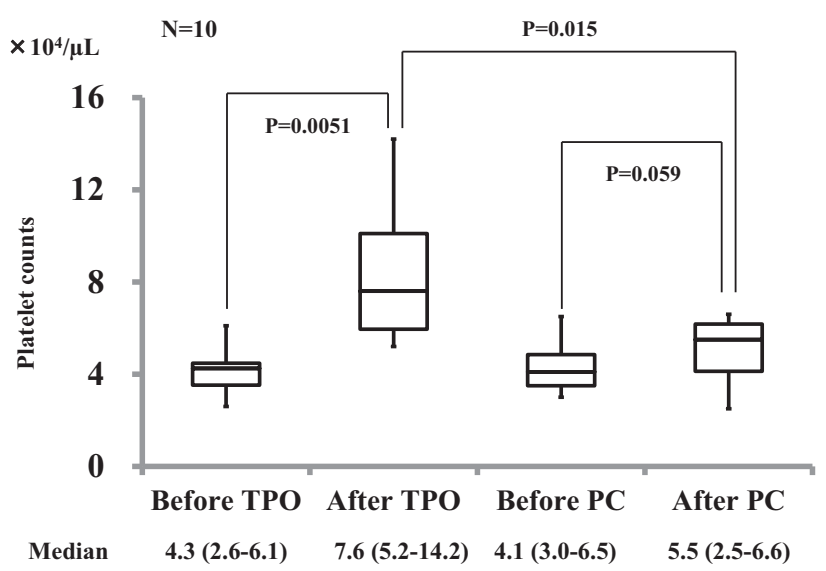

Fig. 3 Comparison of lusutrombopag and platelet transfusion

In 10 patients with a history of platelet transfusion, the effect on the increase in platelet count was compared between lusutrombopag treatment and platelet transfusion. Lusutrombopag (TPO) significantly increased platelet count $(p=0.0051)$, whereas the increase was not significant after platelet transfusion $(\mathrm{PC})(p=0.059)$. Platelet count was significantly higher after TPO than after PC ( $p=$ 0.015).

The top and bottom of the boxes represent the first and third quartiles, respectively, and the height of the boxes represents the interquartile range. The line through the middle of the boxes is the median. The bars represent the minimum and maximum values (range) transfusion. With lusutrombopag, the effect continued for a median number of 9 days after the maximum platelet count was recorded (Table 2, Fig. 2). In addition, lusutrombopag appears to be safer, as no serious AEs and no thrombosis were observed with lusutrombopag (Table 5). In contrast, many previous studies have reported side effects and treatment resistance after platelet transfu$\operatorname{sion}^{16,17,20,21}$.

In the present study, 3 patients did not respond to lusutrombopag (Table 3, Fig. 1a, 1b). Uojima and colleagues reported that splenic volume was negatively correlated with increase in platelet count after lusutrombopag treatment ${ }^{22}$. We investigated correlations between clinical variables and increase in platelet count after lusutrombopag treatment. In our study, spleen size calculated by ultrasound was not a refractory predictor for lusutrombopag effectiveness. However, parameters of renal function (BUN, creatinine, eGFR) were significantly negative correlated with increase in platelet count. The present multivariate analysis also revealed that renal function was a significant factor (Table 4); the increase in platelet count was greater as renal function declined.

Lusutrombopag acts on the human TPO receptor and activates signal transduction pathways that promote proliferation and differentiation of bone marrow cells. It is completely metabolized in the liver, and $83 \%$ of its content is excreted in feces and $1 \%$ in urine. Therefore, there is no pharmacokinetic relationship with renal function. The mechanism underlying the increase in platelets in patients with damaged renal function is interpreted here

Table 5 Adverse events after lusutrombopag treatment

\begin{tabular}{lc}
\hline \multicolumn{1}{c}{ Adverse events $(\mathrm{n}=80)$} & Patients Numbers (percentage) \\
\hline Portal venous thrombosis & $0(0)$ \\
Abdominal pain & $3(3.8)$ \\
Headache & $1(1.3)$ \\
Constipation & $1(1.3)$ \\
Diarrhea & $1(1.3)$ \\
Itch & $1(1.3)$ \\
Cough & $1(1.3)$ \\
Palpitation & $1(1.3)$ \\
Hypertension $(>180$ mm Hg) & $1(1.3)$ \\
Fever $\left(>38.0^{\circ} \mathrm{C}\right)$ & $0(0)$ \\
Rash & $0(0)$ \\
Nausea & $0(0)$ \\
Elevation of AST\&ALT $(>$ upper limit $\times 2)$ & $0(0)$ \\
Elevation of T-Bil $(>$ upper limit $\times 2)$ & $0(0)$ \\
Massive bleeding & $0(0)$ \\
\hline
\end{tabular}

$\mathrm{AST}=$ aspartate aminotransferase, $\mathrm{ALT}=$ alanine aminotransferase, $\mathrm{T}$-bil $=$ total bilirubin 
as follows. TPO receptor is produced in liver, kidney, and bone marrow, and production varies in order to maintain homeostasis ${ }^{2,23}$. TPO 'activity' is diminished in persons with chronic renal failure $(\mathrm{CRF})^{24}$. Conversely, 'plasma TPO level' is elevated in CRF patients ${ }^{25}$. Kazama et al. showed that TPO transcription decreased in the renal cortex but increased in the liver and bone marrow in a CRF rat model. They concluded that increased TPO production in liver and bone marrow might compensate for decreased production in damaged kidneys ${ }^{26}$. In the present study, the increase in platelet count after lusutrombopag administration was greater in patients with diminished renal function, perhaps because in these patients abundant plasma TPO receptors are produced in liver and bone marrow to compensate for the TPO activity. Lusutrombopag stimulates TPO signal transduction and improves activity. Thus, the platelet count appears higher in such patients. The present multivariate analysis of predictors of resistance to lusutrombopag treatment identified no independent predictor, because lusutrombopag was effective in all patients. In other words, few CLD patients exhibited resistance to lusutrombopag treatment.

The primary limitation of this study is that it was conducted at a single center. However, the present sample size was larger than that in previous studies of lusutrombopag. The results identified predictors of increase in platelet count and the usefulness (effectiveness and duration) of lusutrombopag, as compared with platelet transfusion. Interestingly, spleen size on ultrasound was not an independent predictor of increase in platelet count (Table 4), but renal function was, for the first time, identified as an independent predictor. We believe that these results will be useful for the treatment of patients with thrombocytopenia.

Acknowledgements: The authors thank Professor Jeremy Williams of the Department of International Medical Communications at Tokyo Medical University for his editorial review of the English manuscript.

This study was partly supported by a Health Labour Sciences Research Grant from Research on Measures for Intractable Diseases, the Intractable Hepato-Biliary Diseases Study Group in Japan.

Conflict of Interest: None.

\section{References}

1. Poordad F. Review article: thrombocytopenia in chronic liver disease. Aliment Pharmacol Ther. 2007 Nov;26
(Suppl 1):5-11.

2. Afdhal N, McHutchison J, Brown R, et al. Thrombocytopenia associated with chronic liver disease. J Hepatol. 2008;48:1000-7.

3. Giannini EG, Greco A, Marenco S, et al. Incidence of bleeding following invasive procedures in patients with thrombocytopenia and advanced liver disease. Clin Gastroenterol Hepatol. 2010;8:899-902.

4. Perrotta PL, Snyder EL. Non-infectious complications of transfusion therapy. Blood Rev. 2001;15:69-83.

5. Vamvakas EC, Blajchman MA. Transfusion-related mortality: the ongoing risks of allogeneic blood transfusion and the available strategies for their prevention. Blood. 2009;113:3406-17.

6. Furuichi Y, Imai Y, Miyata Y, et al. Branched-chain amino acid-enriched nutrient increases blood platelet count in patients after endoscopic injection sclerotherapy. Hepatol Res. 2016;46:1129-36.

7. Bussel JB, Kuter DJ, Pullarkat V, et al. Safety and efficacy of long-term treatment with romiplostim in thrombocytopenic patients with chronic ITP. Blood. 2009;113:216171.

8. Bussel JB, Cheng G, Saleh MN, et al. Eltrombopag for the treatment of chronic idiopathic thrombocytopenic purpura. N Engl J Med. 2007;357:2237-47.

9. Afdhal NH, Giannini EG, Tayyab G, et al; ELEVATE Study Group. Eltrombopag before procedures in patients with cirrhosis and thrombocytopenia. $N$ Engl J Med. 2012;367:716-24.

10. Tateishi R, Seike M, Kudo M, et al. A randomized controlled trial of lusutrombopag in Japanese patients with chronic liver disease undergoing radiofrequency ablation. J Gastroenterol. 2019;54:171-81.

11. Terrault N, Chen YC, Izumi N, et al. Avatrombopag before procedures reduces need for platelet transfusion in patients with chronic liver disease and thrombocytopenia. Gastroenterology. 2018;155:705-18.

12. Kim ES. Lusutrombopag: First Global Approval. Drugs. 2016;76:155-8.

13. Katsube $\mathrm{T}$, Ishibashi $\mathrm{T}$, Kano $\mathrm{T}$, et al. Population pharmacokinetic and pharmacodynamic modeling of lusutrombopag, a newly developed oral thrombopoietin receptor agonist, in healthy subjects. Clin Pharmacokinet. 2016;55: 1423-33.

14. Gangireddy VG, Kanneganti PC, Sridhar S, et al. Management of thrombocytopenia in advanced liver disease. Can J Gastroenterol Hepatol. 2014;28:558-64.

15. Goh SH, Tan WP, Lee SW. Clinical predictors of bleeding esophageal varices in the ED. Am J Emerg Med. 2005;23: 531-5.

16. Kerkhoffs JL, Eikenboom JC, van de Watering LM, et al. The clinical impact of platelet refractoriness: correlation with bleeding and survival. Transfusion. 2008;48:1959-65.

17. Murphy MF, Waters AH. Clinical aspects of platelet transfusions. Blood Coagul Fibrinolysis. 1991;2:389-96.

18. Meehan KR, Matias CO, Rathore SS, et al. Platelet transfusions: utilization and associated costs in a tertiary care hospital. Am J Hematol. 2000;64:251-6.

19. Hidaka H, Kurosaki M, Tanaka H, et al. Lusutrombopag reduces need for platelet transfusion in patients with thrombocytopenia undergoing invasive procedures. Clin Gastroenterol Hepatol. 2019;17:1192-200.

20. Novotny VM. Prevention and management of platelet transfusion refractoriness. Vox Sang. 1999;76:1-13.

21. Valsami S, Dimitroulis D, Gialeraki A, et al. Current 
trends in platelet transfusions practice: The role of ABO$\mathrm{RhD}$ and human leukocyte antigen incompatibility. Asian J Transfus Sci. 2015;9:117-23.

22. Uojima $\mathrm{H}$, Arase $\mathrm{Y}$, Itokawa $\mathrm{N}$, et al. Relationship between response to lusutrombopag and splenic volume. World J Gastroenterol. 2018;24:5271-9.

23. Kaushansky K. Thrombopoietin. N Engl J Med. 1998;339: 746-54.

24. Gafter U, Bessler H, Malachi T, et al. Platelet count and thrombopoietic activity in patients with chronic renal failure. Nephron. 1987;45:207-10.

25. Linthorst GE, Folman CC, van Olden RW, et al. Plasma thrombopoietin levels in patients with chronic renal failure. Hematol J. 2002;3(1):38-42.

26. Kazama I, Endo Y, Toyama H, et al. Compensatory thrombopoietin production from the liver and bone marrow stimulates thrombopoiesis of living rat megakaryo- cytes in chronic renal failure. Nephron Extra. 2011;1:14756.

(Received, October 29, 2019)

(Accepted, February 6, 2020)

(J-STAGE Advance Publication, March 31, 2020)

Journal of Nippon Medical School has adopted the Creative Commons Attribution-NonCommercial-NoDerivatives 4.0 International License (https://creativecommons.org/licenses/by-nc-nd/4.0/) for this article. The Medical Association of Nippon Medical School remains the copyright holder of all articles. Anyone may download, reuse, copy, reprint, or distribute articles for non-profit purposes under this license, on condition that the authors of the articles are properly credited. 